\title{
Interactive comment on "Hillslope denudation and morphologic response across a rock uplift gradient" by Vincent Godard et al.
}

\author{
Veerle Vanacker (Editor) \\ veerle.vanacker@uclouvain.be \\ Received and published: 14 January 2020
}

Dear authors,

By now, we have received three reviews of your paper. The three reviewers agree on the high quality of the presented work, and they particularly appreciated your integrated work combining high-resolution topographic analyses, $\mathrm{CRN}$ data and numerical modelling.

The reviewers recommend moderate revisions, and I consider the following issues to be the most critical ones:

(1) While the hillslope analyses are clearly described in the methods' section of the manuscript, this is less so for the stream channel analysis and modelling approach. I 
refer here to the comments of Reviewer\#1, and comments 2 and 3 of Reviewer\#2 that will require further elaboration of methodological aspects.

ESurfD

(2) In the paper, you mention that the "hillslope analysis allows to resolve variations in rock uplift, that would not be possible to resolve using stream profile analysis". The three reviewers posted some critical notes here. Reviewer\#1 makes the remark that hillslopes might have a longer memory than stream channels because of the differences in response timescale. A related comment is made by Reviewer\#2 who points to the possibility of having diachronic response to tectonic perturbations within larger watersheds. Reviewer\#3 asks for a discussion of the assumptions of the stream profile analyses that are designed for detachment-limited bedrock streams that are in topographic steady state with respect to rock uplift.

(3) Reviewer\#3 suggests to clarify that this study mainly addresses "the shortwavelength uplift patterns that are superimposed on the regional pattern". This element can be further elaborated in the discussion.

More details are given in the reviewers' comments. Please document the modifications in term of content and line numbers.

Looking forward to receive your revised manuscript.

Interactive comment on Earth Surf. Dynam. Discuss., https://doi.org/10.5194/esurf-2019-50, 2019. 